\title{
Theoretical Analysis of Heat Transfer Through an Idealized Gas Turbine Blade Model with Thermal Barrier Coating
}

\author{
ORHAN AYDIN ${ }^{1 * *}$, MISAO IWATA ${ }^{2}$, NOROI ARAI ${ }^{3}$, and WEN-JEI YANG ${ }^{1, \dagger}$ \\ ${ }^{1}$ Department of Mechanical Engineering and Applied Mechanics, The University of Michigan, Ann Arbor, \\ Michigan, 48109, USA; ${ }^{2} R \& D$ Divison, Noritake Co. Ltd., Aichi, Japan; \\ ${ }^{3}$ Research Center for Advanced Energy Conversion, Nagoya University, Nagoya, Japan
}

In this study, a simplified gas turbine blade model is considered in order to investigate the effectiveness of a new thermal barrier coating material. The model consists of two concentric cylinders with high temperature gas flow in the annular space and with low temperature liquid in the inner cylinder whose exterior surface is coated with thermal barrier coating material having high emissivity. The new coating material, which was developed by the Noritake Co. Ltd., is silica-based glass ceramic. A control volume approach is used for gas and liquid flows, while surface energy balance is used for the surfaces of the inner and outer cylinders. Results obtained for the new coating material are compared with those obtained for the materials with lower emissivities and zero emissivity, that is, the case in which radiation effect is neglected. It is disclosed that a gas turbine blade coated with the new thermal barrier coating material, glass-ceramic, results in higher heat transfer rates, which in turn enhance power output.

Keywords: Gas turbine blade; Thermal barrier coating; Glass-ceramic; Radiative heat transfer; Enhancement

\section{INTRODUCTION}

The gas turbine is a primary energy deliverer not only for vehicular propulsion of such as air, land and water, but also for power generation. Several major factors affect thermal efficiency or specific fuel consumption of a gas turbine plant (Yang, 1997). These include:

\footnotetext{
Received 16 June 2000; In final form 21 June 2000.

* Corresponding author. On leave from Karadeniz Technical University, 61080 Trabzon, Turkey.

Tel.: (734) 764-9910, Fax: (734) 747-3170. E-mail: wjyang@umich.edu
}

(i) Increase in the turbine inlet temperature, namely firing temperature.

(ii) Reduction of cooling air usage.

(iii) Improving component efficiency.

(iv) Cycle enhancement.

The first factor is the concern of this study, and the others are not considered. The turbine inlet temperature is a measure of gas turbine power output. It can be increased in three different ways:

(i) Aerodynamic cooling techniques.

(ii) Thermal barrier coating.

(iii) High performance materials for rotors, nozzles, and buckets.

Gas turbine blades operate under severe stress conditions induced by high gas temperatures and high rotating speeds. There are three methods of protecting the blades:

(i) Internal cooling

(ii) External cooling

(iii) Thermal barrier coating (TBC)

As can be seen, thermal barrier coatings are very important for both increasing the turbine inlet temperature (and therefore turbine power output) and protecting the turbine blades (and therefore increasing their safety and life). Recently, a new TBC material, silica-based glassceramic has been developed by Noritake Co. Ltd. This material is characterized by a nearly constant high emissivity of over 0.80 up to a temperature of $2000^{\circ} \mathrm{C}$. It has been experimentally demonstrated that a metal coated with such material can withstand a very high temperature without melting, while the original material (without the coating) begins to melt.

In this study, a simplified analysis is performed in order to simulate a gas turbine blade placed in a high tempera- 
ture gas flow passage. The results obtained for the new material are compared with the results obtained for two other materials that are commonly used in high-temperature applications, and with results obtained for the case without radiation.

\section{ANALYSIS}

The geometry considered in this study is shown in Figure 1. It consists of two concentric tubes of diameters $d_{1}$ and $d_{2}$. Flue gases flow through the annular space, while the cooling liquid, water, flows through the inner tube. The system geometry given in Figure 1 is a simplified model that simulates an internally-cooled gas turbine blade situated at the turbine inlet. The exterior surface of the outer cylinder is insulated while the exterior surface of the inner cylinder is coated with a thermal barrier coating material of emissivity, $\varepsilon$. Conduction resistance through the inner and outer tubes, and effects of gas absorption and scattering on heat transfer, are neglected.

For the thermal simulation of the system, the control volume method is used. In $x$-direction, 100 control volumes are used for space discretization. Then, the model is divided into four parts for thermal simulation: the outer wall, the inner wall, the annular space through which the hot gases flow, and the inner space through which the cold water flows. In the following, each part is treated separately.

\subsection{The Outer Wall}

From a surface energy balance on the wall of the outer cylinder, which says that

$$
E_{\text {in }}-E_{\text {out }}=0
$$

it follows that

$$
Q_{h}=Q_{r}
$$

where $Q_{h}$ and $Q_{r}$ are the convection heat rate representing heat transfer from the hot fluid to the outer cylinder surface, and the radiation heat rate representing the radiative heat exchange between the outer cylinder surface and the inner cylinder surface, respectively. If their values are substituted into Eq. [1], one obtains

$$
\varepsilon \sigma c T_{1}-\left(\varepsilon \sigma c+d_{r} h_{2}\right) T_{2}+d_{r} h_{2} T_{m, 2}=0
$$

where $T_{1}, T_{2}$ and $T_{m, 2}$ stand for the surface temperature of the inner cylinder, the surface temperature of the outer cylinder, and the mean temperature of the hot fluid, respectively. Throughout each of the control volumes, these temperatures are assumed to be constant. In Eq. [3], $\varepsilon, \sigma$ and $h_{2}$ denote the surface emission, the StefanBoltzman constant and the convection heat transfer coefficient of the hot gas flow, respectively. The term $c$ is used to linearize the radiation term, which is given as

$$
c=\left(T_{1}+T_{2}\right)\left(T_{1}^{2}+T_{2}^{2}\right)
$$

\subsection{The Inner Wall}

Similar to the case for the outer wall, a surface energy balance formulation can be developed for the inner wall. Such an analysis yields

$$
q_{h 2}+q_{r}-q_{h 1}=0
$$

where $q_{h 1}$ and $q_{h 2}$ are the convective heat fluxes representing the convection heat transfer from the inner wall surface to the cold liquid (water), and the convection heat transfer from the hot fluid to the inner wall surface, respectively. The $q_{r}$ represents the radiative heat flux between the outer and inner wall surfaces. Substituting the related values into Eq. [5] yields

$$
-\left(h_{2}+\varepsilon \sigma c+h_{1}\right) T_{1}+\varepsilon \sigma c T_{2}+h_{1} T_{m, 1}+h_{2} T_{m, 2}=0
$$

where $h_{1}$ and $T_{m, 1}$ denote the convection heat transfer coefficient and the mean temperature of the water flowing through the inner tube. As stated earlier, the temperatures through each control volume are assumed to be constant.

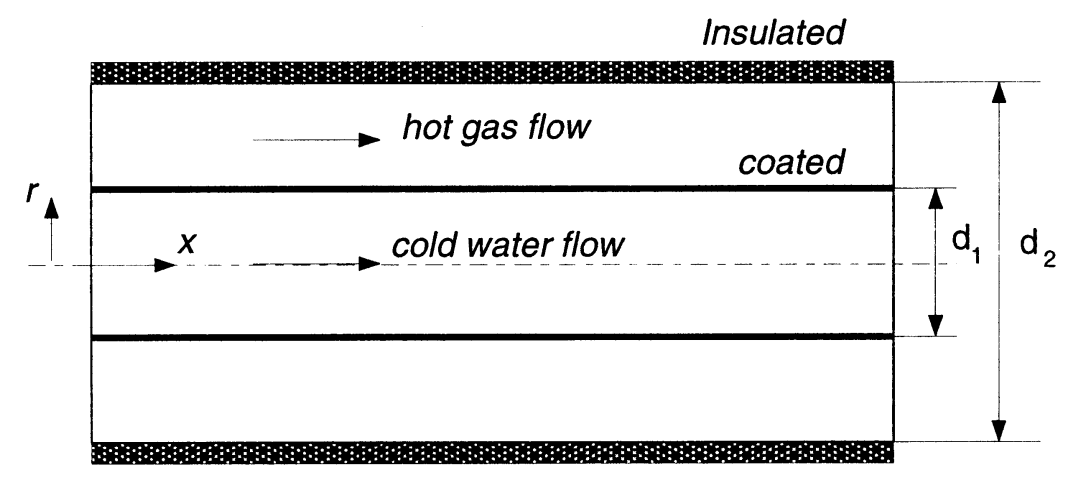

FIGURE 1 A schematic of the physical system under consideration. 


\subsection{The Annular Space (Hot Gas Flow)}

The conservation of energy gives

$$
E_{\text {in }}-E_{\text {out }}+E_{g}=\frac{d E_{s t}}{d t}
$$

where $E_{g}$ and $E_{s t}$ are the energy generation rate and the energy storage in the control volume, respectively. Here, $E_{g}=0$, since there is no conversion from the other forms of the energy to the thermal energy for the system under consideration. Applying this conservation equation for the new control volume yields

$$
\begin{gathered}
m_{2} c_{p, 2} \frac{d T_{m, 2}}{d x}+h_{2} \pi d_{1}\left(T_{m, 2}-T_{1}\right)+h_{2} \pi d_{2}\left(T_{m, 2}-T_{2}\right) \\
=-\rho_{1} \frac{\pi\left(d_{2}^{2}-d_{1}^{2}\right)}{4} c_{p, 2} \frac{d T_{m, 2}}{d t}
\end{gathered}
$$

where $m_{2}, c_{p, 2}$ and $\rho_{2}$ stand for the mass flow rate, the specific heat at constant pressure, and the density of the hot gas, respectively.

\subsection{The Inner Space (Cold Liquid Flow)}

Similar to the case for the hot gas, applying the conservation of energy, Eq. [7], to the inner space through which the cold liquid, water, flows yields

$$
\begin{gathered}
-m_{1} c_{p, 1} \frac{d T_{m, 1}}{d x}+h_{1} \pi d_{1}\left(T_{1}-T_{m, 1}\right) \\
=\rho_{1} \frac{\pi d_{1}^{2}}{4} c_{p, 1} \frac{d T_{m, 1}}{d t}=0
\end{gathered}
$$

where $m_{1}, c_{p, 1}$ and $\rho_{1}$ stand for the mass flow rate, the specific heat at constant pressure, and the density of the water, respectively.
The space and time derivatives seen in Eqs. [8] and [9] are discretized. The convective heat transfer coefficients for the inner and annular space are determined from an empirical correlation for a fully developed, turbulent flow (Incropera \& DeWitt, 1996):

$$
\mathrm{Nu}=0.023 \operatorname{Re}^{4 / 5} \operatorname{Pr}^{n}
$$

where $\mathrm{Nu}, \mathrm{Re}$ and $\mathrm{Pr}$ are the Nusselt number, the Reynolds number, and the Prandtl number, respectively, which are defined as:

$$
\mathrm{Nu}=h d_{c} / k \quad \mathrm{Re}=U d_{c} / \nu \quad \operatorname{Pr}=\nu / \alpha
$$

Here $k, \nu$ and $\alpha$ denote the conduction heat transfer coefficient of fluid, the kinematic viscosity, and the thermal diffusivity, respectively. The power $n$ of the Eq. [9] is 0.4 for the annular space (where the gas temperature is higher than the surface temperature), and 0.3 for the inner space (where the water temperature is lower than the surface temperature). In Eq. [11], $d_{c}$ denotes the characteristic dimension which is taken as $d_{1}$ for the inner space. For the annular space, the Reynolds number definition is

$$
\operatorname{Re}=4 m_{2} / \mu \pi\left(d_{1}+d_{2}\right)
$$

where, $\mu$ is the dynamic viscosity. In evaluating the Nusselt number, $d_{c}$ is $d_{2}-d_{1}$.

\section{RESULTS AND DISCUSSION}

The set of linear equation systems, Eqs. [3], [6], and discretized forms of Eqs. [8] and [9], are solved for different emissivity values of the inner surface, $\varepsilon$. For the new material, the surface emissivity varies as a function of the

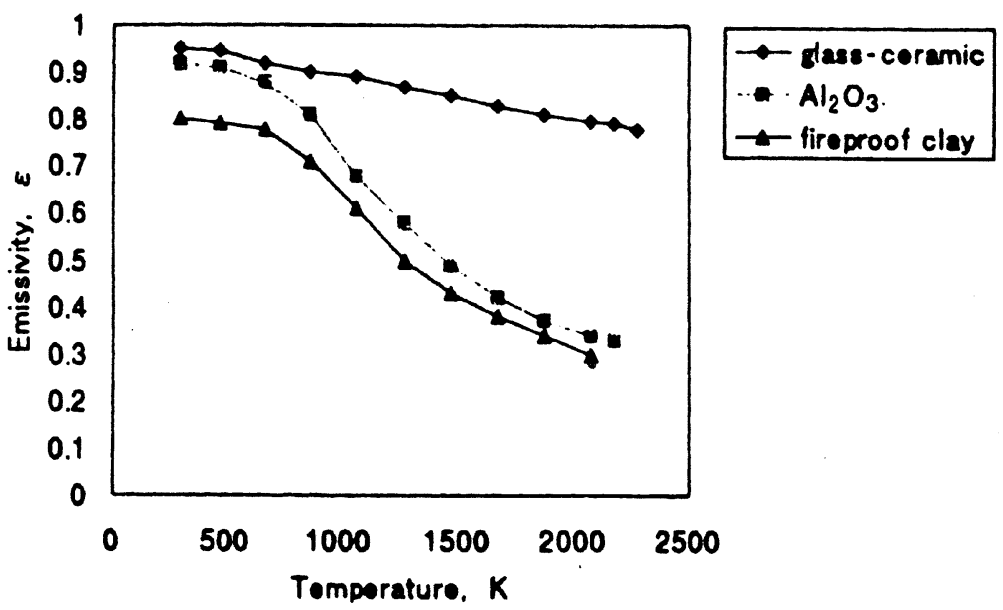

FIGURE 2 Variation of the emissivity, $\varepsilon$, with temperature for different surface coating materials. 

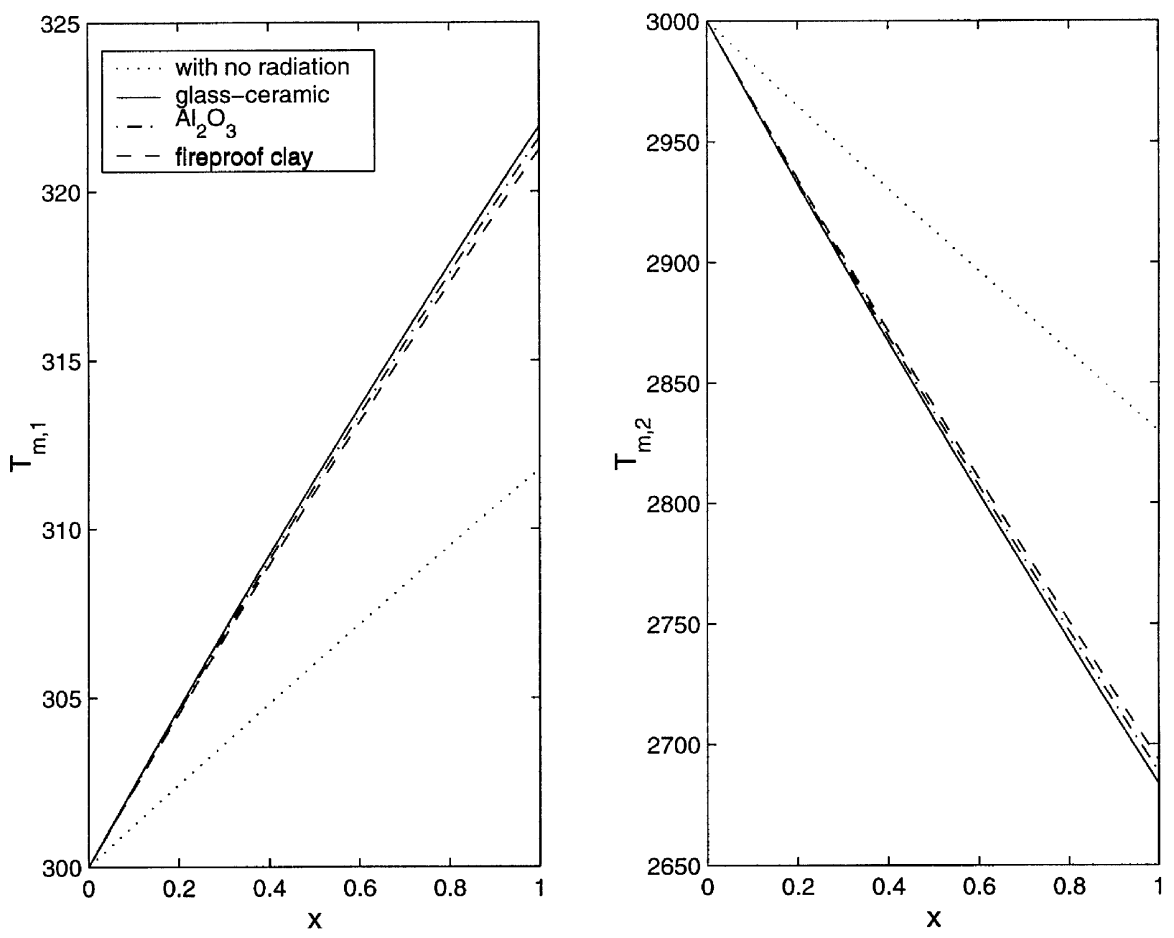

FIGURE 3 Variation of the $T_{m, 1}$ and $T_{m, 2}$ along the tube at $\operatorname{Re}=9.512 \times 10^{3}$ for different surface coating materials.
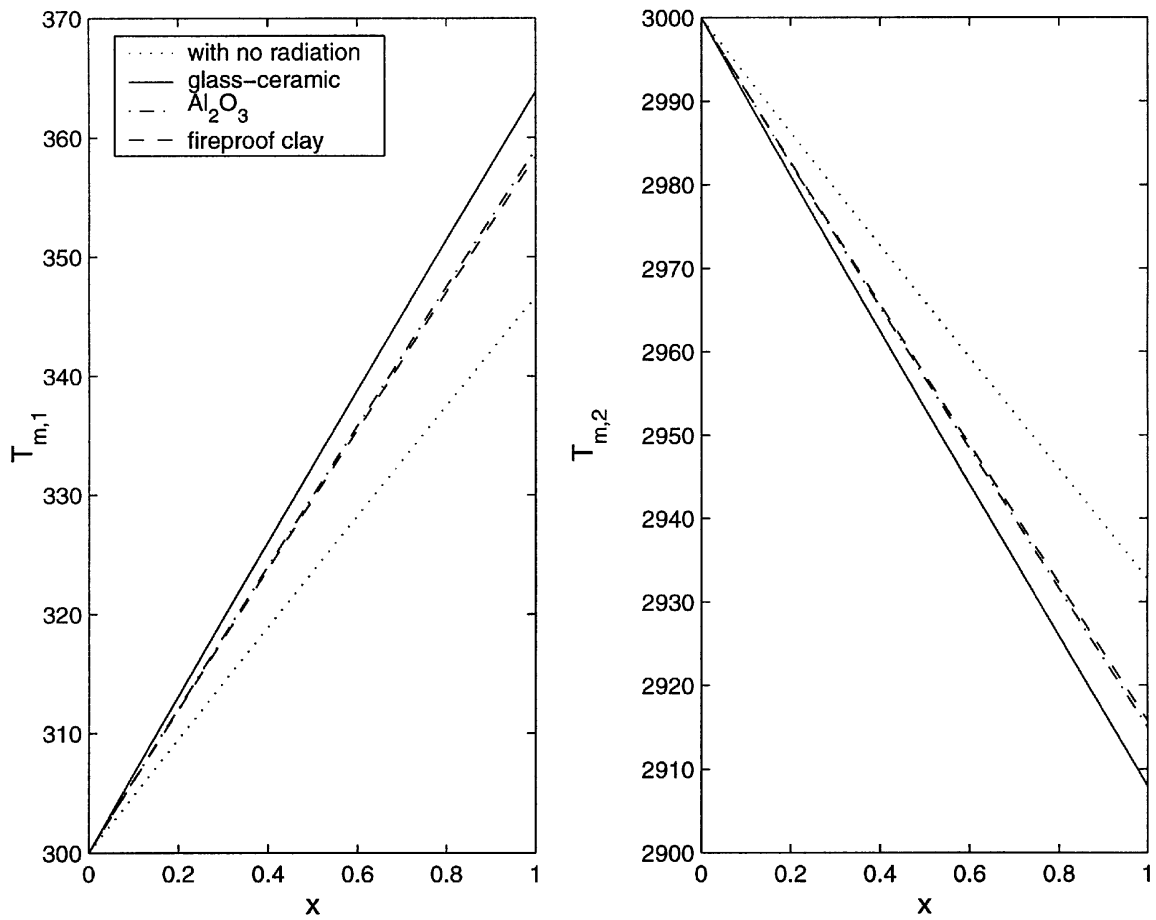

FIGURE 4 Variation of the $T_{m, 1}$ and $T_{m, 2}$ along the tube at $\mathrm{Re}=9.512 \times 10^{4}$ for different surface coating materials.

surface temperature, $T_{s}$ as shown in Figure 2, which can be approximated as

$$
\varepsilon=0.982-9 \times 10^{-5} T_{s}
$$

which is $T_{1}$ here. Two other materials which are commonly used in high-temperature applications are also examined for comparison: $\mathrm{Al}_{2} \mathrm{O}_{3}$ and fire-proof clay. For these materials, the emissivities are determined using: 

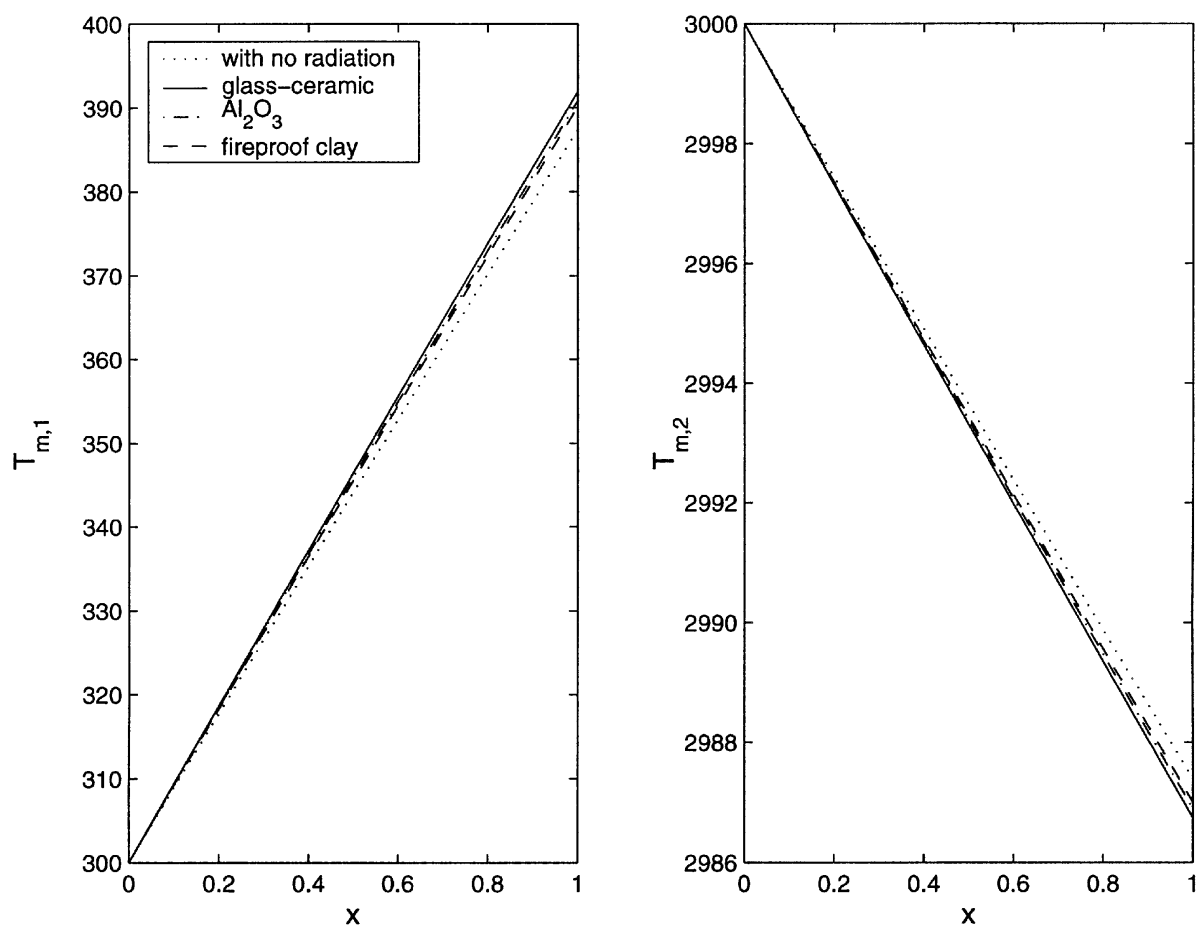

FIGURE 5 Variation of the $T_{m, 1}$ and $T_{m, 2}$ along the tube at $\mathrm{Re}=9.512 \times 10^{5}$ for different surface coating materials.

for $\mathrm{Al}_{2} \mathrm{O}_{3}$ and

$$
\begin{aligned}
\varepsilon= & 0.89+3.1 \times 10^{-4} T_{s}-6.63 \\
& \times 10^{-7} T_{s}^{2}+1.84 \times 10^{-10} T_{s}^{3}
\end{aligned}
$$

$$
\begin{aligned}
\varepsilon= & 0.79+1.82 \times 10^{-4} T_{s}-4.73 \\
& \times 10^{-7} T_{s}^{2}+1.23 \times 10^{-10} T_{s}^{3}
\end{aligned}
$$

for fireproof clay.

The length of the concentric tubes is $L=1 \mathrm{~m}$. The inlet temperatures for the hot gas and cold water are $3000^{\circ} \mathrm{K}$, and $300^{\circ} \mathrm{K}$, respectively. The gas properties used are: $c_{p, 2}=2726 \mathrm{~J} / \mathrm{kgK}, \mu_{2}=955 \times 10^{-7} \mathrm{~N}^{\mathrm{s}} / \mathrm{m}^{2}, \rho_{2}=0.32 \mathrm{~kg} / \mathrm{m}^{3}$, $\mathrm{Pr}_{2}=0.536$ and $k_{2}=0.486 \mathrm{~W} / \mathrm{mK}$, and the water properties are: $c_{p, 1}=4179 \mathrm{~J} / \mathrm{kgK}, \rho_{1}=997 \mathrm{~kg} / \mathrm{m}^{3}$, and $U_{1}=0.3 \mathrm{~m} / \mathrm{s}$.

In addition to the effect of the surface emissivity, that of the mass rate of the hot gas flow, or Reynolds number, on the heat transfer are also predicted. The gas mass flow rate is varied as $0.25,2.5$ and 25 , which are equivalent to $\operatorname{Re}$ of $9.512 \times 10^{3}, 9.512 \times 10^{4}$ and $9.512 \times 10^{5}$, respectively. The steady-state solutions are achieved when the temperature differences in each control volume become less than $10^{-5}$.

At $m_{2}=0.25 \mathrm{~kg} / \mathrm{s}$ for different coating materials, Figure 3 show the changes of the hot gas mean temperature, $T_{m, 1}$, and the cold water mean temperature, $T_{m, 2}$, in the $x$ direction at steady-state. It is seen that all three materials give better results than the uncoated surface and that the new material, the glass-ceramic, has a higher exit mean water temperature and a lower exit mean gas temperature than the other two surface coating materials, $\mathrm{Al}_{2} \mathrm{O}_{3}$ and fireproof clay. This is an indication of higher heat transfer enhancement in the new surface coating material. A similar effect is observed for $m_{2}=2.5 \mathrm{~kg} / \mathrm{s}\left(\operatorname{Re}=9.512 \times 10^{4}\right)$ and for $m_{2}=25 \mathrm{~kg} / \mathrm{s}\left(\operatorname{Re}=9.512 \times 10^{5}\right)$, as illustrated in Figures 4 and 5 , respectively. It is found that an increase in the mass flow rate or the Reynolds number reduces the significance of using the surface coating materials because of an increase in the convection heat transfer effect. Therefore, at a very high Reynolds number (for example, $\operatorname{Re}=9.512 \times 10^{5}$ ), the effect of the surface radiation heat transfer is suppressed by an increase in convection heat transfer contribution, as depicted in Figure 6.

\section{CONCLUSIONS}

A simplified heat transfer analysis is performed on two concentric tubes with hot gas flowing through the annular space and cold liquid (water) flowing in the inner tube. The outer surface of the inner tube is coated with a special thermal barrier coating material. The influence of the Reynolds number of the hot gas flow on the heat transfer is determined by changing the mass flow rate of the hot gas flow. Results are obtained for the spatial variations of the mean temperatures of the hot gas and cold water at steady state. The study has revealed that the use of coating materials on the inner surface having high emissivities has 

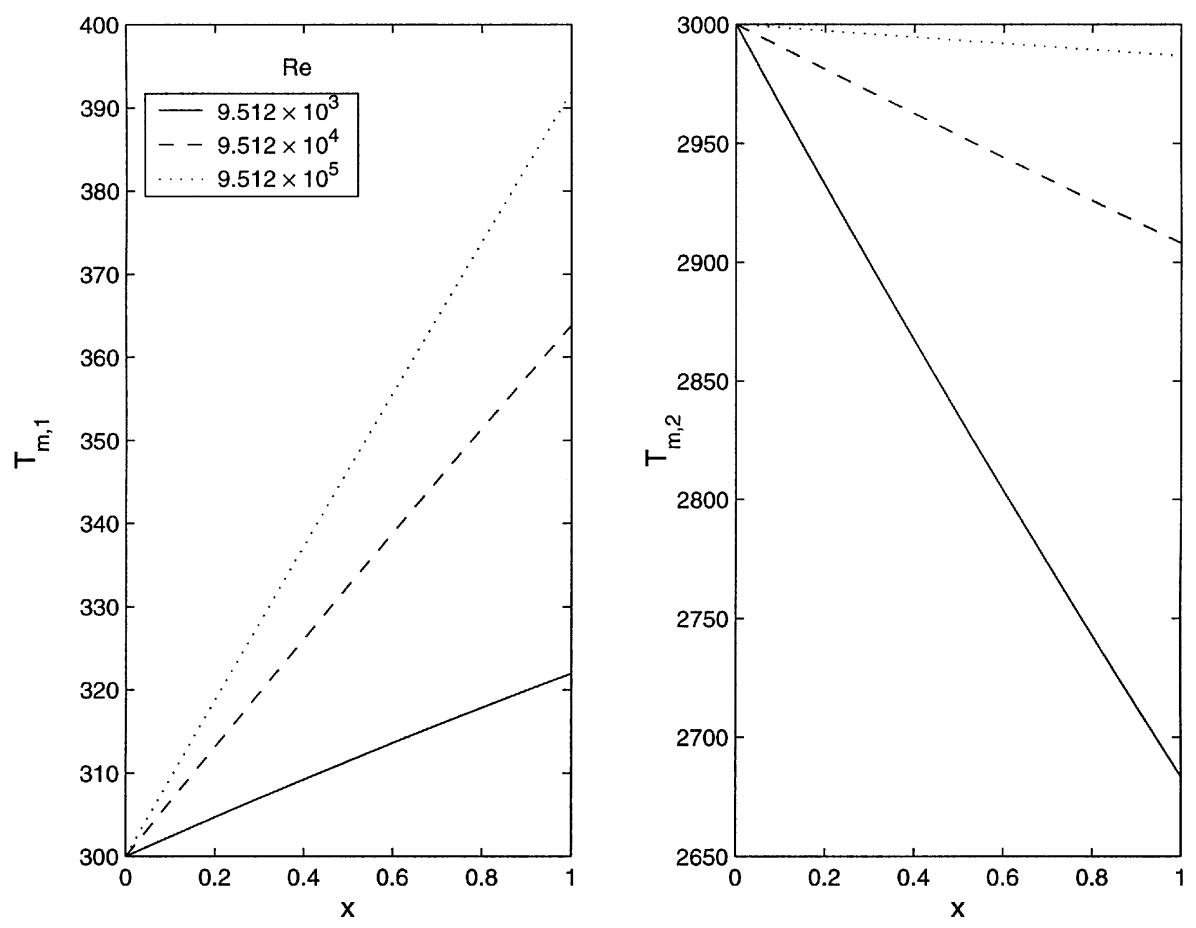

FIGURE 6 Variation of the $T_{m, 1}$ and $T_{m, 2}$ along the tube with the glass-ceramic coating for different Reynolds numbers.

resulted in heat transfer enhancement. The new coating material, glass-ceramic, is superior to the other two commonly used coating materials, $\mathrm{Al}_{2} \mathrm{O}_{3}$ and fireproof clay, due to its higher surface emissivity. At a high Reynolds number, the significance of radiation, and therefore, surface coatings, diminishes due to an increase in convective heat transfer contribution

\section{NOMENCLATURE}

$c_{p} \quad$ specific heat at constant pressure, $\mathrm{J} / \mathrm{kgK}$

$d_{1}$ inner diameter, $\mathrm{m}$

$d_{2} \quad$ outer diameter, $\mathrm{m}$

$d_{r} \quad$ diameter ratio

E energy, W

$h$ convection heat transfer coefficient, $\mathrm{W} / \mathrm{m}^{2} \mathrm{~K}$

$k$ heat conductivity, $\mathrm{W} / \mathrm{mK}$

$L \quad$ length, m

$\mathrm{Nu}$ Nusselt number

Pr Prandtl number

$Q$ heat rate, $\mathrm{W}$

$q$ heat flux, $\mathrm{W} / \mathrm{mK}$

$\mathrm{Re}$ Reynolds number

$T$ temperature, $\mathrm{K}$

$T_{1} \quad$ inner surface temperature, $\mathrm{K}$

$T_{2}$ outer surface temperature, $\mathrm{K}$

$t$ time, s
$U \quad$ velocity, $\mathrm{m} / \mathrm{s}$

$r, z$ coordinates defined in Figure 1

Greek Symbols

$\alpha \quad$ thermal diffusivity, $\mathrm{m}^{2} / \mathrm{s}$

$\varepsilon \quad$ surface emissivity

$\sigma \quad$ Stefan-Boltzman coefficient, $\mathrm{W} / \mathrm{M}^{2} \mathrm{~K}^{4}$

$\rho$ density $\mathrm{kg} / \mathrm{m}^{3}$

$\nu \quad$ kinematic viscosity, $\mathrm{m}^{2} / \mathrm{s}$

$\mu \quad$ dynamic viscosity, $\mathrm{kg} / \mathrm{ms}$

\section{Subscripts}

$c \quad$ characteristic

$g$ generation

$m$ mean

$s$ surface

st storage

1 water

2 gas

\section{REFERENCES}

Incropera, F. P. and DeWitt, D. P. (1996) Introduction to Heat Transfer, John Wiley Sons, New York.

Yang, W. J. (1997) Reduction of Specific Fuel Consumption in Gas Turbine Power Plants, Energy Convrs. Mgmt, 38, 1219-1224. 

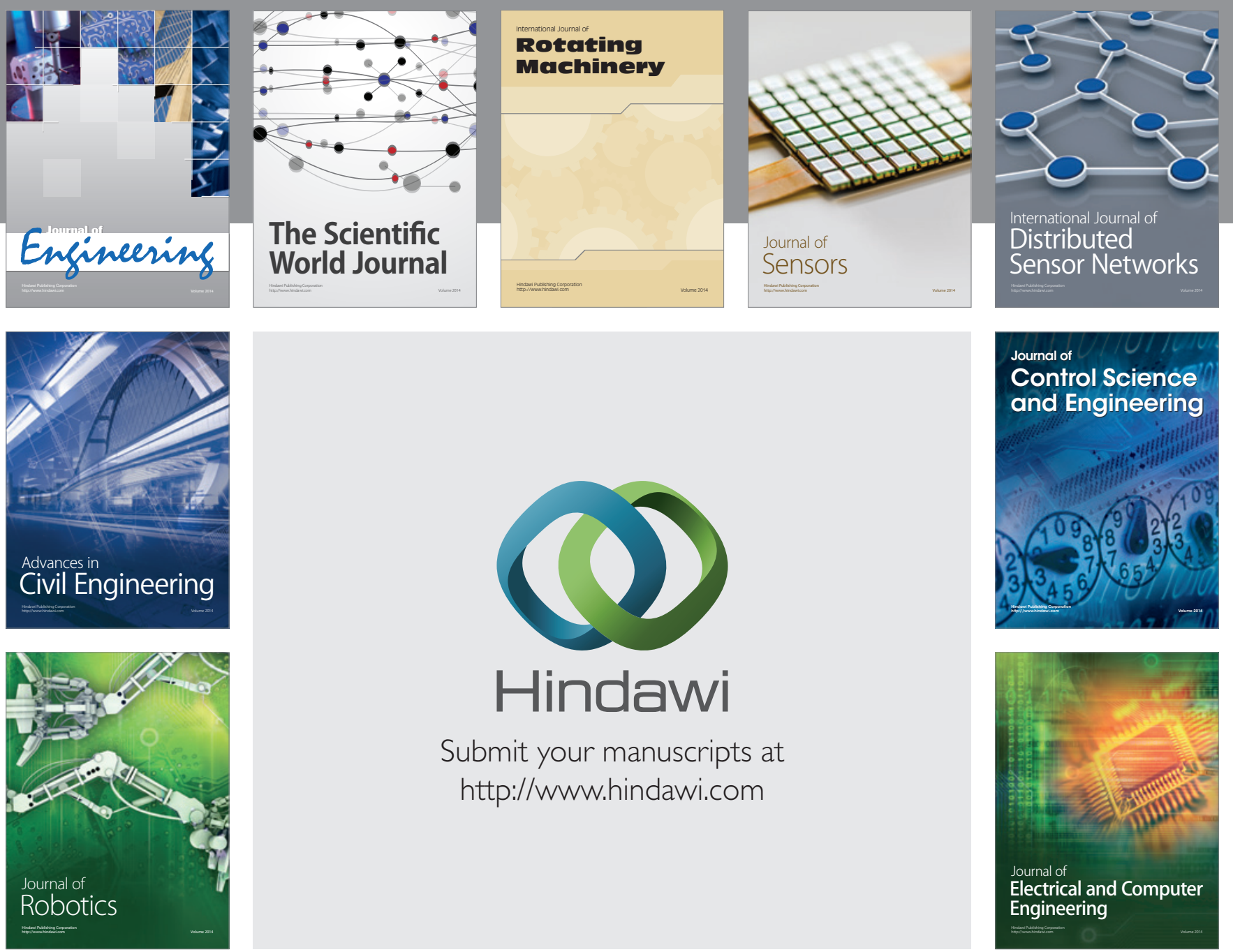

Submit your manuscripts at

http://www.hindawi.com
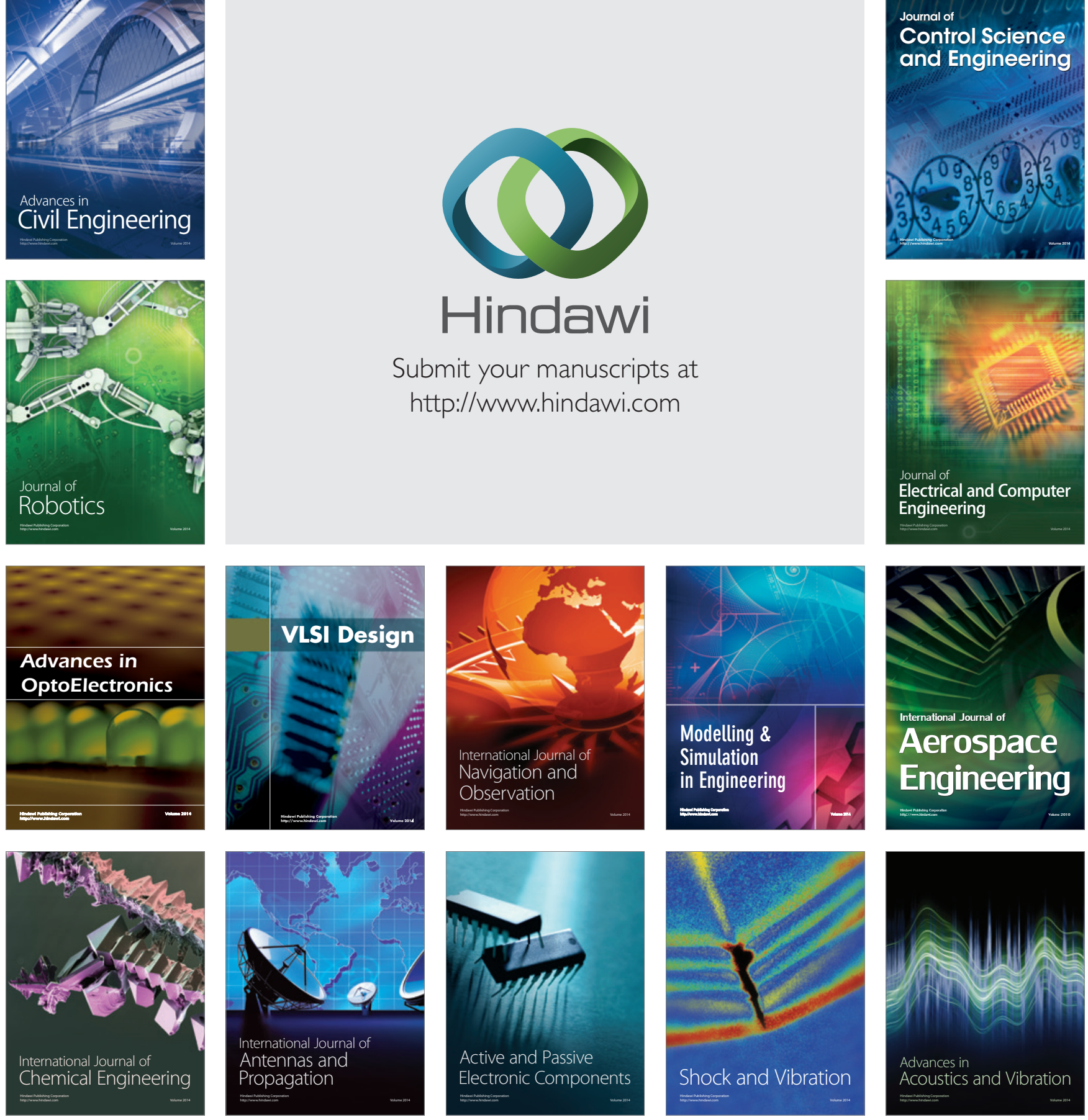